\title{
Nanosized Particles of Silica and Its Derivatives for Applications in Various Branches of Food and Nutrition Sectors
}

\begin{abstract}
Mohammad Reza Kasaai
Department of Food Science and Technology, Sari Agricultural Sciences and Natural Resources University, Khazar Abad Road, Km. 9, P.O. Box 578, Sari, Mazandaran, Iran
\end{abstract}

Correspondence should be addressed to Mohammad Reza Kasaai; reza_kasaai@hotmail.com

Received 28 July 2015; Revised 17 November 2015; Accepted 19 November 2015

Academic Editor: Jorge M. Seminario

Copyright (C) 2015 Mohammad Reza Kasaai. This is an open access article distributed under the Creative Commons Attribution License, which permits unrestricted use, distribution, and reproduction in any medium, provided the original work is properly cited.

\begin{abstract}
Nanosized particles of silica and its derivatives have been identified as versatile for a broad range of science, technology, and engineering applications. In this paper, an effort has been made to provide a short review from the available literature information on their applications in various branches of food and nutrition sectors. The information provided in this paper describes various parameters affecting their performances and efficiencies. The properties and applications of nanosilica and its derivatives have been compared with microsilica and bulk-silica for their performances. The use of nanosized particles of silica and its derivatives provides a number of advantages. Their efficiencies and performances are significantly higher than those of the traditional ones.
\end{abstract}

\section{Introduction}

Science and technology have many challenges in food industries due to the need to produce high quality of food ingredients or food products. For instance, pathogen detection, encapsulation, delivery of bioactive compounds, packing systems, food protection, and food storage are some examples of developing applications of nanotechnology that could improve production processes in order to achieve products with better characteristics and functionalities in food industries $[1,2]$.

Materials with at least one dimension in nanometerlength scale and a large surface-to-volume ratio create novel properties and phenomena [2]. They become ideal for applications that involve food composite materials, chemical reactions, controlled and immediate release of substances in active and functional packaging technologies, and energy storage in intelligent packaging [2].

High quality of food components or food products can be achieved by means of nanotechnology. Nanotechnology can address all of the requirements on food safety (controlling microbial growth and delaying oxidation) [3]. In addition, it provides new food packaging materials with improvement in both performance and properties (mechanical, barrier, and antimicrobial), together with monitoring the conditions of food during transport and storage.

Applications of nanosized particles in food packaging to achieve high quality of food products probably are a major section of its applications in food nanotechnology. Polymer nanocomposites consist of polymer matrices and fillers with at least one dimension within 1-100 nm. Polymers containing nanosized particles exhibit unique combinations of properties not achievable with traditional composites. Unlike traditional composites, these novel fillers often alter the properties of the entire polymer matrix while, at the same time, imparting new functionality because of their chemical composition and nanosized components [4]. Polymer nanocomposites incorporating nanosized particles are a novel class of composite materials. Nanocomposites produce from low volume fractions of fillers, which affect the entire matrix, due to their large surface area to volume ratio, through an interaction zone. The unique nature of these particles presents unique opportunities to create a wide range of multifunctional polymer composites [4]. They have been shown significant improvements in mechanical properties at very low filler weight fractions. Applications of nanosized silica in food and nutrition are given in the following sections. 
A number of important issues should be taken into consideration for applications of nanotechnology in food technology. The most important ones are the safety concerns due to possible migration of nanoparticles from packaging materials into foods and their eventual toxicological effects [3]. The major disadvantage of nanoscale materials for food and nutrition application is their toxicity. Some of limited scientific data about migration of nanoparticles into foods are given in the following. Previous studies have shown the possibility of nanomaterials migration from packaging or containers to foodstuff [3]. Materials that are $300 \mathrm{~nm}$ or less in diameter can be taken up by individual human cells [5], and nanomaterials less than $70 \mathrm{~nm}$ can even be taken up by a cell's nuclei, where they can cause major damage $[6,7]$. The effects of exposing human lung's submucosal cells to $\mathrm{SiO}_{2}$ of various sizes $(10,150$, and $500 \mathrm{~nm})$, for $2-24 \mathrm{~h}$ in vitro, have been studied [8]. The authors concluded the nanotoxicity of $10 \mathrm{~nm}$ $\mathrm{SiO}_{2}$ on the submucosal cells is associated with inflammation. Toxic effect was not observed with amorphous silica with 150 and $500 \mathrm{~nm}$.

The major applications of nanotechnology could be in food packaging due to a wide range of benefits, such as improvements in barrier, mechanical, and antimicrobial properties and performances. Many researches are addressed to the setup of new food packaging materials, in which polymer nanocomposites incorporate nanoparticles [4].

Nanosized particles of silica and its derivatives have been employed in various branches of food and nutrition sectors. However, these particles have not been used as an ingredient of food products. They have been used in food and nutrient components analysis as a supporting material for making column chromatography or increasing sensitivity or efficiency for glucose biosensors; as food packaging as fillers or protecting agent to increase shelf-life of food products; as edible (flavor) carriers; as an adsorbent of moisture; or as a clarifying agent to remove impurities and undesirable particles remaining in beverages. In this report, an effort has been made to provide a short review from some available literature information on the applications of nanosized particles of silica and silica derivatives in various branches of food and nutrition sectors: as fillers in food packaging; as flavor carriers; as supporting materials for food and nutrient components analysis; or as an adsorbent or a clarifying agent. All of the above-mentioned applications of the nanosized particles result in products with better quality, characteristics, or functionalities in food industries in comparison with employing of larger particles with the same composition.

\section{Presenting Different Types of Silica for Applications in Various Food and Nutrition Sectors}

Synthetic silica (colloidal silica, silica gels, and precipitated silica), which is pure and produced mostly in amorphous powder forms, can be used for this study [9]. Silica gels are widely employed in food industry as flavor carriers [10]. Amorphous sol-gel $\mathrm{SiO}_{2}$ is nontoxic and safe, whereas the solgel entrapment of delicate chemicals in its inner pores results in pronounced chemical and physical stabilization of the entrapped actives [10]. Porous sol-gel-made silica particles have been used as encapsulation matrices for controlled release of substances in food and pharmaceutical sectors [11]. Sol-gel process is also widely used to produce silicon dioxide, glass, and ceramic materials [9]. Sol-gel silica glasses have been used as containers in food packaging [12, 13]. Sol-gel silica glasses do not swell or change structure under $\mathrm{pH}$ or temperature variations and are not suitable for other aspects of food and nutrition applications [10]. Sol-gel $\mathrm{SiO}_{2}$ doped with liquid organic process has never resulted in formation of pure silicon oxide, as the residual valence electrons on siloxane ( $\mathrm{Si}-\mathrm{O}-\mathrm{Si}$ ) have the ability to react with water resulting in a surface covered with silanol groups ( $\mathrm{Si}-$ $\mathrm{OH}$ ), possessing a highly polar behavior. A large number of unreacted silanol groups exist at surface of doped sol-gel glasses, thereby creating a large inner porosity, which gives place to the impressive variety of chemical applications of doped sol-gel silica [10].

\section{Parameters Corresponding to Particle Sizes Affecting the Properties of Materials}

Micro- and nanoscience and technology refer to materials size characterization with dimensions on the order of micrometers and nanometers. A number of physical effects have different significance on the micrometer scale compared to nanometer scale [14-16]. The small dimension of nanomaterials such as nanofillers and their specific processing methods affects their defect structure, which has a significant influence on the properties of these materials [16]. Nanofillers possess small mechanical, optical, and electrical defects compared to microscale fillers [16]. When the dimensions of particles reduce into nanoscale level, the properties of the particles differ significantly from those of bulk materials and micron-scale particles. Thus, variations in melting temperature, color, magnetization, and charge capacity are often observed [3]. The small size of the fillers leads to an exceptionally large interfacial area in composites [3]. Nanofillers are characterized for at least one dimension in nanometer-length scale (within $1-100 \mathrm{~nm}$ in size). The term nanocomposites refers to composite materials that contain typically low amounts of nanostructured materials. Typically $1-7 \%$ of nanoparticles is added to the materials to form composite materials [2, 3]. Most nanocomposites being considered in the packaging sector are based on low volume fractions [2, 3]. The total surface area of $1 \mathrm{gr}$. of polymer particles having a diameter of $0.1 \mu \mathrm{m}$ would be about $60 \mathrm{~m}^{2}$, and the total surface area is inversely proportional to the diameter [17].

\section{Description of Various Applications of Nanosized Silica Particles in Food and Nutrition Sectors}

4.1. Use of Nanosized Silica Particles in Fabrication of Sensors. $\mathrm{SiO}_{2}$ nanosized particles have been used to construct nanobiosensors $[18,19]$. The sensitivity and performance of 
biosensors are being improved by using nanomaterials for their constructions and their size characterizations. The use of nanomaterials has allowed the introduction of many new signal transduction technologies in biosensors because of their nanosized dimensions [20-22]. The principal advantages to use biosensors are high specificity and sensitivity, being simple to use, low-cost instrumentation, fast response times, minimum sample pretreatments, and ease of transport for in situ measurement [23].

Glucose biosensor is an environmental friendly diagnosis device to measure glucose in food, nutrition, and clinical sectors. A variety of glucose biosensors with a high sensitivity and an excellent reproducibility based on nanotechnology have been developed [24-28]. Among these developments, the nanoparticles enhanced glucose biosensors are interesting biosensors [28]. The unprotected Pt nanoclusters (average size $2 \mathrm{~nm}$ ) mixed with the nanoscale $\mathrm{SiO}_{2}$ particles (average size $13 \mathrm{~nm}$ ) were used as a glucose oxidase immobilization carrier to fabricate the amperometric glucose biosensor [29]. The bioactivity of glucose oxidase (GOx) immobilized on the composite was maintained and the as-prepared biosensor demonstrated high sensitivity $\left(3.85 \mu \mathrm{AmM}^{-1}\right)$ and good stability in glucose solution. The $\mathrm{Pt}-\mathrm{SiO}_{2}$ biosensor showed a detection limit of $1.5 \mu \mathrm{M}$ with a linear range from 0.27 to $4.08 \mathrm{mM}$. In addition, the biosensor can be operated under wide $\mathrm{pH}$ range $(\mathrm{pH}$ 4.9-7.5) without great changes in its sensitivity.

The body naturally regulates blood glucose levels as a part of metabolic homeostasis. It is the primary source of energy for the body's cells and blood lipids. It is an important nutrient substance. Thus, it is desirable to develop a reliable, a reproducible, and a sensitive method for its measurement. The ability to obtain a rapid, an accurate, and a precise glucose measurement is an essential aspect in nutrition and clinical sectors. Glucose biosensors offer a possibility of carrying out a simple and a rapid analytical procedure [30, 31].

Sol-gel derived silicates have been proved to be highly compatible with enzymes [32]. With the development of material science, it provides more opportunities to immobilize various biomolecules which show high selectivity and sensitivity to the target analytes and therefore fabricate biosensors with a good performance. A series of monodispersed nanosilica film enhanced glucose biosensors with different thicknesses were fabricated by using a dip-coating method. The suitable thickness for a nanosized $\mathrm{SiO}_{2}$ film provided optimal environment for glucose oxidase to retain its bioactivity. A key factor to fabricate a high sensitivity glucose biosensor was to enlarge the enzyme loading on the surface. The high surface area of the small nanosized $\mathrm{SiO}_{2}$ particles in a thick film increased the surface enzyme loading, resulting in a high performance of a biosensor. But if the film is too thick, the performance of the sensor would decrease, because the mass transfer of glucose and $\mathrm{H}_{2} \mathrm{O}_{2}$ becomes difficulty $[28,33,34]$.

Glucose can be oxidized to gluconolactone in the presence of glucose oxidase, with a parallel conversion of dissolved $\mathrm{O}_{2}$ to $\mathrm{H}_{2} \mathrm{O}_{2}$. Glucose oxidase produces hydrogen peroxide which is directly proportional to the concentration of glucose. The $\mathrm{H}_{2} \mathrm{O}_{2}$ formed near electrode can thus be detected quantitatively (either by oxidation or reduction) $[28,34]$;

$$
\begin{aligned}
& \text { Glucose }+\mathrm{O}_{2} \underset{\text { oxidation }}{\stackrel{\text { Glucose oxidase }}{\longrightarrow}} \text { D-glucose-1,5-lactone } \\
& +\mathrm{H}_{2} \mathrm{O}_{2} \\
& \mathrm{H}_{2} \mathrm{O}_{2}+\text { O-dianisidine } \underset{\text { oxidation }}{\stackrel{\text { Peroxidase }}{\longrightarrow}} \mathrm{H}_{2} \mathrm{O} \\
& \quad+\text { oxidized chromogen }
\end{aligned}
$$

The majority of biosensors for glucose measurement have focused on the amperometric detection of glucose. The electrochemical response of glucose with a nanosized silica biosensor revealed a linear behavior in the range of 0.005$2.5 \mathrm{mM}$ glucose in a phosphate buffer solution with $\mathrm{pH} 7.2$ $[28,34,35]$.

\subsection{Use of Nanosized Silica Particles in Food Packaging.} Generally, polymer composites made by silicates as fillers with a low level of concentration exhibited enhancement of mechanical and physicochemical properties in comparison with the original polymers. Mechanical strength is generally required to maintain the structural integrity and barrier properties of thin films. Nanoparticles have been proved to be a promising option in order to improve mechanical and barrier properties of materials for making nanocomposites [36]. It could be inferred that the nanoparticles could affect water vapor permeability (WVP), oxygen permeability (OP), and longitudinal strength of polymeric films which could yield significant barrier and mechanical properties advantages [37]. The improvements result in protection of food products from deterioration, prolong shelf-life of foods, and maintain food quality. Gas permeation through polymer nanocomposites follows a mass transport mechanism similar to that in a semicrystalline polymer matrix. During gas permeation, gas molecules are initially adsorbed on the surface of the polymer and then diffuse through the polymer. In a nanocomposite, the polymer phase is considered to be permeable, and silicate platelets are considered to be nonpermeable to gases [38]. Nanosized silica as an inorganic material at appropriate level of contents was introduced into polylactic acid (PLA) as an organic component with a biodegradable property to prepare biodegradable organic-inorganic hybrid coating materials by sol-gel process [39]. Water vapor and gas barrier properties of the final composite materials, $\mathrm{PLA} / \mathrm{SiO}_{2}$, were improved. The final products can be used as coating films in food packaging. The barrier property of a polymer material can be described in terms of permeability, which is dependent on the diffusion coefficient of gas and the solubility coefficient of that gas in the polymer matrix $[12,13,38-41]$. Polycaprolactone (PCL) filled with $\mathrm{SiO}_{2}$ nanosized particles can be used as a polymer-based nanocomposite system [42]. The size and morphology of monodispersed silica particles have been examined by transmission electron microscopy (TEM) and $\mathrm{X}$-ray diffraction analysis. TEM analysis has revealed that the silica nanoparticles are nearly perfect with no agglomerated spheres and with an average diameter of 100-200 nm, while 
X-ray analysis has shown that silica nanopowders are completely amorphous [42]. Young's modulus of PCL/modified $\mathrm{SiO}_{2}$ nanocomposites was increased about $25 \%$ with respect to that found for the PCL homopolymer. These results are attributed to a good compatibility, good dispersion of nanoparticles, and good interfacial adhesion to the matrix [42]. Nylon 6 filled with 5\% of silica nanosized particles with $50 \mathrm{~nm}$ in diameter yields increase of $15 \%$ in tensile strength, $23 \%$ in Young's modulus, and $78 \%$ in impact strength [43].

Aluminum is used as a thin film, a thin layer, a multilayer film, a cask (can) for beverages (fruit juices and beer), and food coatings and packaging $[12,13,44]$. A thin layer of few nanometers silica on the surface of aluminum (as a thin film, a thin layer, or a multilayer) protects the metal surface from oxidizing and reduces its reflectivity $[12,13,45]$.

\section{Use of Nanosized Silica as Food Additives in Food Technology}

Calcium and magnesium silicate $\left(\mathrm{CaSiO}_{3} \cdot \mathrm{XH}_{2} \mathrm{O}, \mathrm{MgSiO}_{3}\right.$. $\mathrm{XH}_{2} \mathrm{O}$ ), calcium aluminum silicate, and aluminum silicate have been used as anticaking agents in food industries to prevent caking in food products [common salt, seasoning salt (e.g., a mixture of onion or garlic powder with common salt), dehydrated vegetable and fruit powders, soup and sauce powders, and baking powder] [44, 46-48]. Calcium silicate and silicon dioxide have been also used as nutrient sources and food supplements in food industries [49].

Bentonite, montmorillonite clay, a complex hydrated aluminum silicate $\left[\mathrm{Al}_{2} \mathrm{SiO}_{9}(\mathrm{OH})_{x}\right]$ with exchangeable cations, and frequently sodium ions have been employed as clarifying agents. It is a selective adsorbent for proteins, pectins, phenolic compounds, and plant pigments such as chlorophyll and carotenoids. The adsorption and separation processes are based on attraction between positive charges of the latter components and the negative charges of the silicates. Nanosized silica is used as a fining agent for wines to preclude protein precipitation. Nanosized silica particles have stronger adsorption ability than that of larger sized particles for separation of food components having positive charges $[46,47,50]$.

Nanomembranes are used to separate liquids and gases at the molecular level. Silica nanoparticles embedded in a carbon based may help to produce gases free of impurities. Because of the nanocomposite's ability to trap molecularsized impurities, it could be further used in processes such as biomolecules purification and sea water desalination [51]. Nanomembranes are commonly made from polymers based nanocomposites with a thickness less than $100 \mathrm{~nm}$. Such nanomembranes include polymers combined with a mesh of silica nanosized particles. The size of the holes in the mesh restricts or allows the passage of different sized molecules. Nanomembranes combined with nanosized silica have been used for purification of polluted water and removal of carbon dioxide and other pollutants from liquids and gases [51].

\section{Use of Nanosized Silica in Chromatography to Analysis of Food Components}

The most common support for the stationary phase of chromatography columns is highly pure, spherical, microporous particles of silica that are permeable to solvent and have a surface area of several hundred square meters per gram. A silica surface possesses up to $8 \mu \mathrm{mol}$ of silanol groups $(\mathrm{Si}-\mathrm{OH})$ per square meter [45]. Another example for stationary phase is porous graphic carbon deposited on silica. The column is packed with tiny particles of silica which are attached to long hydrocarbon molecules. This material exhibits increased retention of nonpolar compounds relative to their retention by bonded phases such as $\mathrm{C}_{8}$. It has high affinity for polar compounds and performs separations of isomeric compounds that cannot be done with $\mathrm{C}_{18}$ [45]. Monolithic silica column is a single, porous silica rod polymerized from liquid precursors. The inside of silica skeleton (with a network of $2 \mu \mathrm{m}$ pores) contains a finer network of $\sim 13 \mathrm{~nm}$ pores [45]. Approximately $80 \%$ of the volume of the rod is empty space. The surface area is $300 \mathrm{~m}^{2} \cdot \mathrm{g}^{-1}$, which compares favorably with that of excellent stationary phase materials [45]. After fabrication, the silica rod is tightly encased in a chemically resistant plastic tube made of polyether ether ketone (PEEK). Employing monolithic silica columns for separation of different components enables us to increase the flow rate in liquid chromatography up to $10 \mathrm{~mL} \cdot \mathrm{min}^{-1}$, while retaining a good separation. The finer the particle sizes for the stationary phase, the greater the resolution and the slower the flow rate of the column. This results in a faster analysis as well as a shorter time of analysis [45]. Microporous silica with a controlled pore size provides 10000-16000 plates per meter. Particles with different pore sizes can be mixed to give a wider molecular size separation range. For instance, a stationary phase with a pore size range of $13-100 \mathrm{~nm}$ can be used to separate a wide range of molecular weight $(0.5-150 \mathrm{kDa})$ [45]. A very finely divided (10 $\mathrm{nm}$ pore size) ultrapure silica gel has been used to modify chemically at the surface by bonding to octadecylsilyl groups [38]. To minimize any interaction with basic compounds, the particles should be encapsulated carefully to cover most of the remaining silanol groups [38].

Columns in different chromatography procedures are used to separate several materials present in unknown samples. For example, in the separation of caffeine from theobromine in a chocolate sample, caffeine is more soluble than theobromine in hydrocarbon on the silica surface. Therefore, caffeine sticks to the coated silica nanosized particles in the column more strongly than theobromine does [45]. Separation of aroma extracts of roasted coffee was performed by gas chromatography on silica gel [47]. Separation of flavor isolates into individual components may be achieved by gas chromatography with fused-silica capillary columns [46]. The volatile flavor compounds were separated on a crosslinked 5\% phenylmethyl silicone fused silica capillary column installed in GC equipped with a flame ionization detector [52]. Thin-layer chromatography on silica gel impregnated with silver nitrate has been used to distinguish between isomeric pairs of glycerides. The silver ions are complexed 
by double bonds of unsaturated triglycerides, whose mobility is thus reduced [45]. Fats may be fractionated on a silica-gel column and its nonpolar fraction is eluted with a petroleum ether-diethyl ether mixture [46]. Separation of many higher boiling food compounds may be achieved by high performance liquid chromatography with silica as a stationary phase [46].

\section{Conclusions}

In this short review, the following conclusions were made:

(1) Use of nanosized silica as a filler for fabrication of nanocomposite materials is a promising option in order to improve various (water vapor, oxygen, or other gas barrier or mechanical ones) properties, to increase efficiency and to extend shelf-life of food products in food packaging technology.

(2) The sensitivity and accuracy of glucose sensors increase by applying nanosized silica. Use of nanosized silica in a glucose sensor allows one to measure glucose with a greater reproducibility and low concentrations.

(3) Use of nanosized silica in chromatography columns to separate different food components takes a shorter time in comparison with microsized silica.

(4) A few nanometers of a thin-layer made-up nanosized silica protect the surface of aluminum from oxidative reaction and reduce its reflectivity.

(5) Use of nanosized silica instead of traditional particles (micron-scale fillers) improves the efficiency of materials (such as anti-caking, clarifying, adsorption agents) and reduces consumption of raw materials.

\section{Conflict of Interests}

The author of this paper declares that there is no conflict of interests regarding the publication of this paper.

\section{References}

[1] H. Hernández-Sánchez and G. F. Gutiérrez-López, "Introduction," in Food Nanoscience and Nanotechnology, H. HernándezSánchez and G. F. Gutiérrez-López, Eds., chapter 1, pp. 1-3, Springer, New York, NY, USA, 2015.

[2] M. D. Sanchez-Garcia and J. M. Lagaron, "Nanocomposites for food packaging," in Kirk-Othmer Encyclopedia of Chemical Technology, pp. 1-11, John Wiley \& Sons, New York, NY, USA, 2010.

[3] C. Silvestre, D. Duraccio, and S. Cimmino, "Food packaging based on polymer nanomaterials," Progress in Polymer Science, vol. 36, no. 12, pp. 1766-1782, 2011.

[4] M. Avella, M. E. Errico, G. Gentile, and M. G. Volpe, "Nanocomposite sensors for food packaging," in Food Nanoscience and Nanotechnology, H. Hernandez-Sanchez and G. F. GutierrezLopez, Eds., chapter 53, pp. 501-510, Springer, New York, NY, USA, 2015.
[5] M. C. Garnett and P. Kallinteri, "Nanomedicines and nanotoxicology: some physiological principles," Occupational Medicine, vol. 56, no. 5, pp. 307-311, 2006.

[6] M. Chen and A. von Mikecz, "Formation of nucleoplasmic protein aggregates impairs nuclear function in response to $\mathrm{SiO}_{2}$ nanoparticles," Experimental Cell Research, vol. 305, no. 1, pp. 51-62, 2005.

[7] M. Geiser, B. Rothen-Rutishauser, N. Kapp et al., "Ultrafine particles cross cellular membranes by non-phagocytic mechanisms in lungs and in cultured cells," Environmental Health Perspectives, vol. 113, no. 11, pp. 1555-1560, 2005.

[8] J. McCarthy, I. Inkielewicz-Stępniak, J. J. Corbalan, and M. W. Radomski, "Mechanisms of toxicity of amorphous silica nanoparticles on human lung submucosal cells in vitro: Protective effects of fisetin," Chemical Research in Toxicology, vol. 25, no. 10, pp. 2227-2235, 2012.

[9] I. A. Rahman and V. Padavettan, "Synthesis of silica nanoparticles by sol-gel: size-dependent properties, surface modification, and applications in silica-polymer nanocomposites-a review," Journal of Nanomaterials, vol. 2012, Article ID 132424, 15 pages, 2012.

[10] R. Ciriminna and M. Pagliaro, "Sol-gel microencapsulation of odorants and flavors: opening the route to sustainable fragrances and aromas," Chemical Society Reviews, vol. 42, no. 24, pp. 9243-9250, 2013.

[11] S. R. Veith, M. Perren, and S. E. Pratsinis, "Encapsulation and retention of decanoic acid in sol-gel-made silicas," Journal of Colloid and Interface Science, vol. 283, no. 2, pp. 495-502, 2005.

[12] R. Coles, D. McDowell, and M. J. Kirwan, Food Packaging Technology, Blackwell Publishing, CRC Press, Oxford, UK, 2003.

[13] L. Robertson G, Food Packaging: Principles and Practices, Taylor \& Francis, Boca Raton, Fla, USA, 2005.

[14] G. A. Mansoori, Principles of Nanotechnology: Molecular-Based Study of Condensed Matter in Small Systems, World Scientific, Hackensack, NJ, USA, 2005.

[15] P. Sanguansri and M. A. Augustin, "Nanoscale materials development-a food industry perspective," Trends in Food Science \& Technology, vol. 17, no. 10, pp. 547-556, 2006.

[16] J. Gubicza, Defects in Nanomaterials, Woodhead Publishing Limited, Cambridge, UK, 2012.

[17] P. Kumar, K. P. Sandeep, S. Alavi, V. D. Truong, and R. E. Gorga, "Preparation and characterization of bio-nanocomposite films based on soy protein isolate and montmorillonite using melt extrusion," Journal of Food Engineering, vol. 100, no. 3, pp. 480489, 2010.

[18] A. L. Simonian, T. A. Good, S.-S. Wang, and J. R. Wild, "Nanoparticle-based optical biosensors for the direct detection of organophosphate chemical warfare agents and pesticides," Analytica Chimica Acta, vol. 534, no. 1, pp. 69-77, 2005.

[19] F. Luo, J. Yin, F. Gao, and L. Wang, "A non-enzyme hydrogen peroxide sensor based on core/shell silica nanoparticles using synchronous fluorescence spectroscopy," Microchimica Acta, vol. 165, no. 1, pp. 23-28, 2009.

[20] T. Vo-Dinh, B. M. Cullum, and D. L. Stokes, "Nanosensors and biochips: frontiers in biomolecular diagnostics," Sensors and Actuators B: Chemical, vol. 74, no. 1-3, pp. 2-11, 2001.

[21] T. Haruyama, "Micro- and nanobiotechnology for biosensing cellular responses," Advanced Drug Delivery Reviews, vol. 55, no. 3, pp. 393-401, 2003. 
[22] A. G. Mendoza-Madrigal, J. Chanona-Pérez, L. GuadarramaFernández et al., "Nanobiosensors in food science and technology," in Food Nanoscience and Nanotechnology, H. HernandezSanchez and G. F. Gutierrrez-Lopez, Eds., Food Engineering Series, pp. 213-230, Springer, Mexico City, Mexico, 2015.

[23] E. Touloupakis, G. Basile, E. Pace, M. T. Giardi, and F. di Costa, "Successes in the development and application of innovative techniques," in Biotechnological Application of Photosynthetic Proteins: Biochips, Biosensors and Biodevices, M. T. Giaridi and E. V. Piletska, Eds., chapter 18, pp. 209-213, Springer, New York, NY, USA, 2006.

[24] J. Yu, S. Liu, and H. Ju, "Glucose sensor for flow injection analysis of serum glucose based on immobilization of glucose oxidase in titania sol-gel membrane," Biosensors and Bioelectronics, vol. 19, no. 4, pp. 401-409, 2003.

[25] J. Wang and M. Musameh, "Enzyme-dispersed carbonnanotube electrodes: a needle microsensor for monitoring glucose," Analyst, vol. 128, no. 11, pp. 1382-1385, 2003.

[26] S. G. Wang, Q. Zhang, R. Wang et al., "Multi-walled carbon nanotubes for the immobilization of enzyme in glucose biosensors," Electrochemistry Communications, vol. 5, no. 9, pp. 800803, 2003.

[27] K. J. Cash and H. A. Clark, "Nanosensors and nanomaterials for monitoring glucose in diabetes," Trends in Molecular Medicine, vol. 16, no. 12, pp. 584-593, 2010.

[28] H. Yang and Y. Zhu, "A high performance glucose biosensor enhanced via nanosized $\mathrm{SiO}_{2}$," Analytica Chimica Acta, vol. 554, no. 1-2, pp. 92-97, 2005.

[29] H. Yang and Y. Zhu, "Glucose biosensor based on nano-SiO and 'unprotected' Pt nanoclusters," Biosensors and Bioelectronics, vol. 22, no. 12, pp. 2989-2993, 2007.

[30] G. C. Luxton, "Diabetes monitoring with out-of-laboratory tests," Clinical Biochemistry, vol. 26, no. 1, pp. 19-20, 1993.

[31] M. Romito, "Biosensors: diagnostic workhorses of the future," The South African Journal of Chemistry, vol. 89, pp. 93-99, 1993.

[32] S. Sakka, Handbook of Sol-Gel Science and Applications, Kluwer Academic Publishers, Boston, Mass, USA, 2004.

[33] A. E. G. Cass, G. Davis, G. D. Francis et al., "Ferrocene-mediated enzyme electrode for amperometric determination of glucose," Analytical Chemistry, vol. 56, no. 4, pp. 667-671, 1984.

[34] X. Ren, X. Meng, and F. Tang, "Preparation of Ag-Au nanoparticle and its application to glucose biosensor," Sensors and Actuators B: Chemical, vol. 110, no. 2, pp. 358-363, 2005.

[35] S. Yabuki and F. Mizutani, "Modifications to a carbon paste glucose-sensing enzyme electrode and a reduction in the electrochemical interference from L-ascorbate," Biosensors and Bioelectronics, vol. 10, no. 3-4, pp. 353-358, 1995.

[36] M. Avella, J. J. De Vlieger, M. E. Errico, S. Fischer, P. Vacca, and M. G. Volpe, "Biodegradable starch/clay nanocomposite films for food packaging applications," Food Chemistry, vol. 93, no. 3, pp. 467-474, 2005.

[37] M. Zenkiewicz, J. Richert, and A. Rózański, "Effect of blow moulding ratio on barrier properties of polylactide nanocomposite films," Polymer Testing, vol. 29, no. 2, pp. 251-257, 2010.

[38] G. Choudalakis and A. D. Gotsis, "Permeability of polymer/clay nanocomposites: a review," European Polymer Journal, vol. 45, no. 4, pp. 967-984, 2009.

[39] G. Bang and S. W. Kim, "Biodegradable poly(lactic acid)based hybrid coating materials for food packaging films with gas barrier properties," Journal of Industrial and Engineering Chemistry, vol. 18, no. 3, pp. 1063-1068, 2012.
[40] K. Bhunia, S. Dhawan, and S. S. Sablani, "Modeling the oxygen diffusion of nanocomposite-based food packaging films," Journal of Food Science, vol. 77, no. 7, pp. 29-38, 2012.

[41] R. K. Bharadwaj, "Modeling the barrier properties of polymerlayered silicate nanocomposites," Macromolecules, vol. 34, no. 26, pp. 9189-9192, 2001.

[42] M. Avella, M. E. Errico, G. Gentile, and M. G. Volpe, "Nanocomposite sensors for food packaging," in Nanotechnological Basis for Advanced Sensors, J. P. Reithmaier, P. Paunovic, W. Kulisch, C. Popov, and P. Petkov, Eds., NATO Science for Peace and Security Series B: Physics and Biophysics, chapter 53, pp. 501510, Springer, New York, NY, USA, 2011.

[43] Y. Ou, F. Yang, and A. Yu, "A new conception on the toughness of nylon 6/silica nanocomposite prepared via in situ polymerization," Journal of Polymer Science B: Polymer Physics, vol. 36, no. 5, pp. 789-795, 1998.

[44] T. P. Coultate, Food Chemistry: The Chemistry of Its Components, The Royal Society of Chemistry, Cambridge, UK, 4th edition, 2002.

[45] D. C. Harris, Quantitative Chemical Analysis, W.H. Freeman and Company, New York, NY, USA, 6th edition, 2003.

[46] O. R. Fennema, Food Chemistry, Marcel Dekker, New York, NY, USA, 3rd edition, 1996.

[47] H.-D. Belitz, W. Grosch, and P. Schieberle, Food Chemistry, Springer, Berlin, Germany, 4th edition, 2009.

[48] D. E. Newton, Food Chemistry, Facts on File Inc., New York, NY, USA, 2007.

[49] F. Aguilar, U. R. Charrondiere, B. Dusemund et al., "Scientific opinion of the panel on food additives and nutrient sources added to food on calcium silicate, silicon dioxide and silicic acid gel added for nutritional purposes to food supplements following a request from the European commission," European Food Safety Authority Journal, vol. 1132, pp. 1-24, 2009.

[50] V. L. Singleton, "Adsorption of natural phenols from beer and wine," Master Brewers Association of Americas Technical Quarterly, vol. 4, no. 4, pp. 245-253, 1967.

[51] C. J. M. van Rijin and W. Nijdam, "Nano-membranes," in Encycopedia of Nano-Science and Nanotechnology, H. S. Nalwa, Ed., vol. 7, pp. 47-77, American Scientific Publishers, Valencia, Calif, USA, 2004.

[52] R. K. Richardson and S. Kasapis, "Rheological methods in the characterization of food biopolymers," in Instrumental Methods in Food and Beverage Analysis, D. Wetzel and G. Charalambous, Eds., Elsevier, Amsterdam, The Netherlands, 1998. 

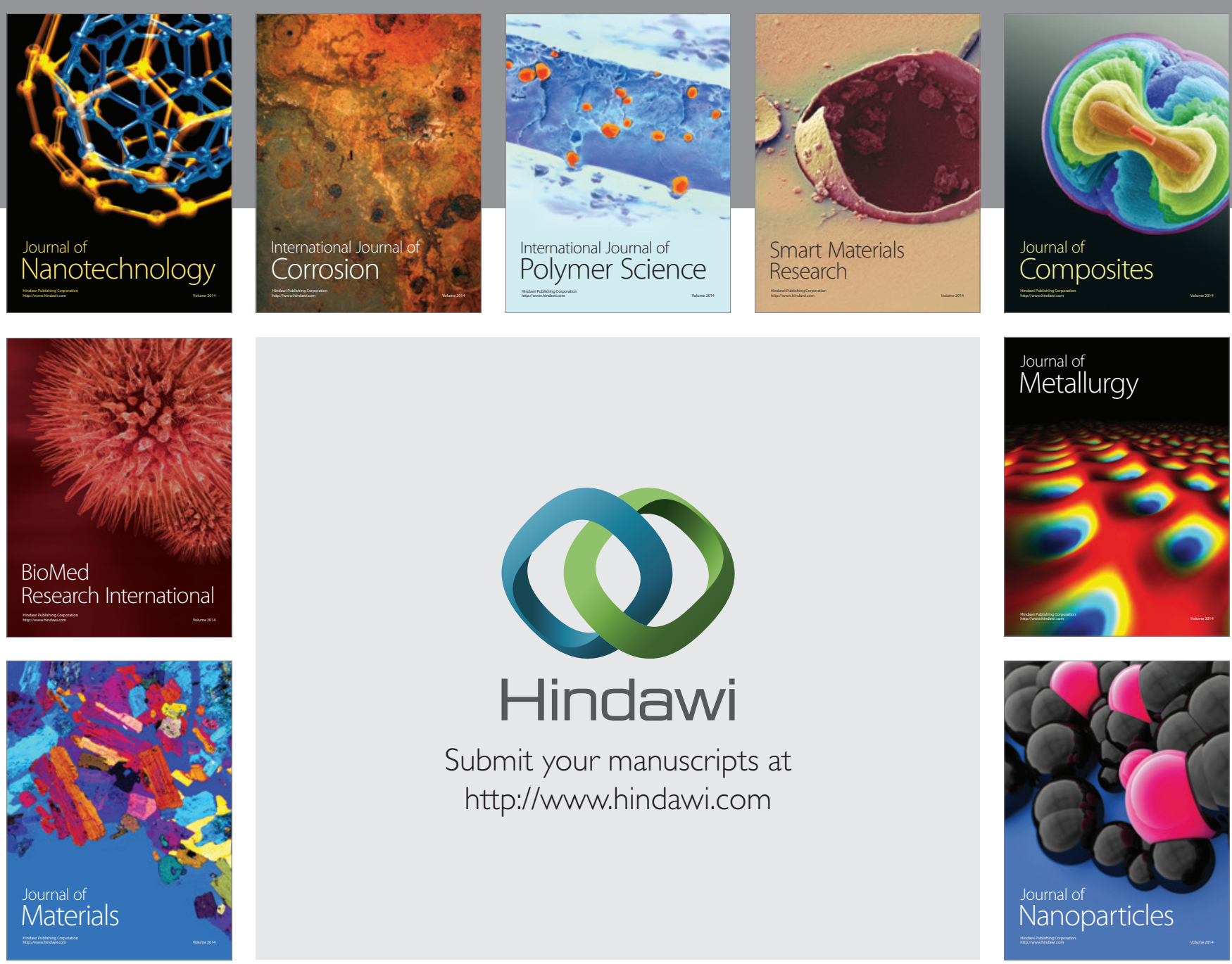

Submit your manuscripts at http://www.hindawi.com
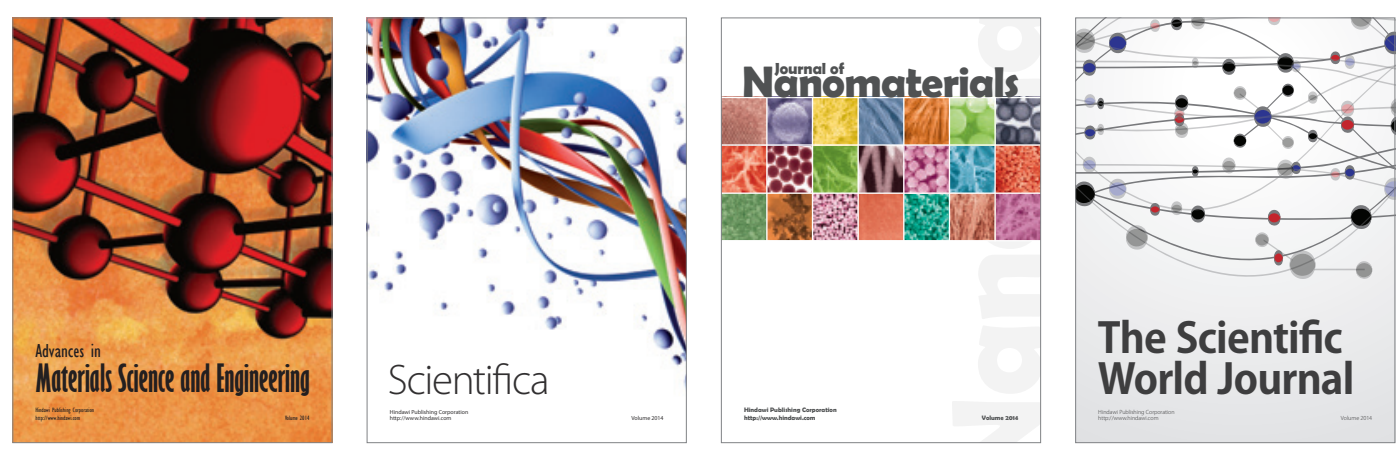

\section{The Scientific World Journal}
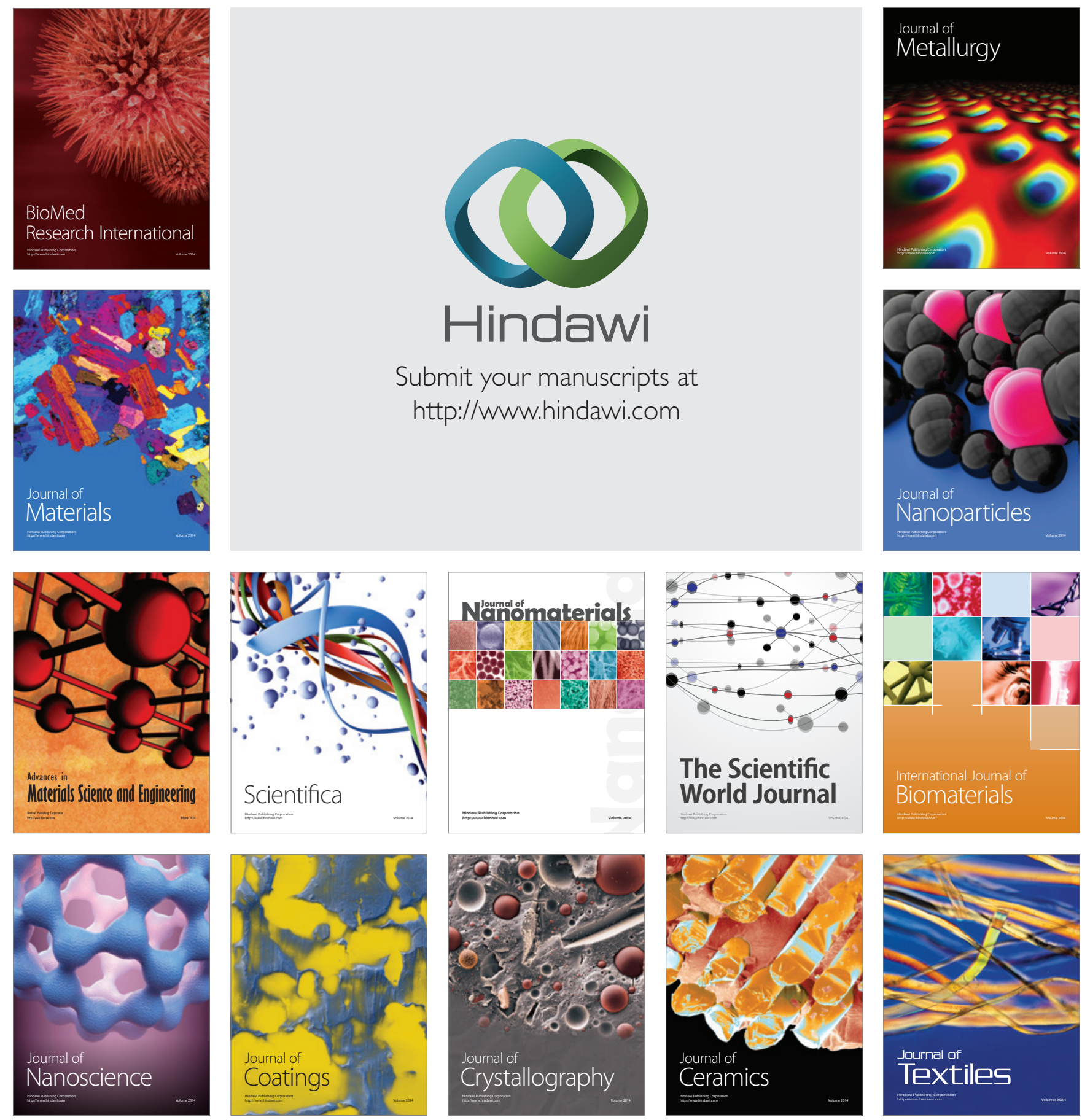